http://jmscr.igmpublication.org/home/ ISSN (e)-2347-176x ISSN (p) 2455-0450 crossref DOI: https://dx.doi.org/10.18535/jmscr/v9i5.06

\title{
Clinicopathological Study of Malignant Melanoma at Tertiary Care Centre- SMS Medical Collage, Jaipur
}

\author{
Authors \\ Sharma Priyanka ${ }^{1}$, Saini Sunita ${ }^{2 *}$, Gupta Karuna ${ }^{3}$ \\ ${ }^{1}$ Senior Resident, Department of Pathology, SMS Medical Collage, Jaipur \\ ${ }^{2}$ Assistant Professor, Department of Pathology, Govt SK Medical Collage, Sikar \\ ${ }^{3}$ Senior Professor, Department of Pathology, SMS Medical Collage, Jaipur \\ *Corresponding Author \\ Saini Sunita
}

\begin{abstract}
Introduction: Malignant melanoma is a type of skin cancer which is arises from the pigment-producing cells - melanocytes. Malignant Melanomas typically occur in the skin but rarely occur in the mouth, intestines or eye (uveal melanoma). Also may occur anywhere on the body. Symptoms of malignant melanoma include a new, unusual growth or a change in an pre-existing mole. Treatment may involve surgical excision, radiation, medication or in some cases, chemotherapy.

Objectives: To document the pattern of clinico-pathological spectrum of malignant melanoma cases at SMS Medical college, Jaipur.

Methods: The present study was a retrospective study conducted in SMS Medical college, department of pathology, Jaipur between 2013 to 2019. During this period total 90 cases received and diagnosed on biopsy.

Results: We received 90 cases in our department with age range from 10 to 86 years. $M$ : $F$ ratio was 1.2:1 with male predominance. Most common age group is 51-60 year. In our study melanoma are predominantly non cutaneous origin (53) like rectum followed by anal canal, nasal-sinonasal, oral cavity and lymph node, followed by cutaneous melanoma (37). Majority of histologic subtype of melanoma are nodular melanoma 17 (45.9\%) followed superficial spreading melanoma 13(35.1) then acrolantigeeous 7(18.9). Half (50\%) of the excisional biopsies were at Clark's level III.

Conclusion: Malignant melanoma is aggressive tumor, more common in male then female. Nodular melanoma and superficial spreading was commonest histologic type malignant melanoma in our population.

Keyword: malignant melanoma, nodular, Clark's level.
\end{abstract}

\section{Introduction}

Malignant melanoma, which develop from the melanocytes, is an important disease entity as it causes majority $(75 \%)$ of deaths related to skin cancer. $^{(1)}$
Malignant melanoma (MM) is a potentially lethal and aggressive tumor of melanocytic origin. it comprises only $3 \%$ of all skin cancers diagnosed every year, it accounts for approximately $75 \%$ of all skin cancer-related deaths. ${ }^{(2)}$ 
According to the World Health Organization, the cases of malignant cases worldwide is increasing faster than any other cancer ${ }^{\text {(3) }}$

The rate of increasing incidence varies geographically with "high incidence regions" like Australia and "moderate incidence regions" like Canada and USA. ${ }^{(4)}$ In India, it is an uncommon disease. $^{(2)}$

The current study was done to determine the clinical and pathological characteristics of malignant melanoma diagnosed in patients in SMS medical college and hospital, Jaipur, Rajasthan.

\section{Material and Method}

A retrospective study was conducted on 90 consecutive cases diagnosed histopathologically as Malignant melanoma between 2013 and 2019 in the Department of Pathology of the SMS Medical college, jaipur, India. Clinical history like previous therapy and other investigation details were taken from hospital records. Tumor size and gross appearance were obtained from pathology report. All biopsies were taken from grossly characteristic areas. Sections were made from paraffin embedded specimen and stained with hematoxylin and eosin ( $\mathrm{H}$ and $\mathrm{E})$ routinely. Histopathological parameters of the tumor were evaluated for cell type, invasion (based on Clarke's system), pigmentation, mitotic activity, and dermal lymphocytic infiltration. Immunohistochemical markers such as HMB 45, melan A and S100 protein were used on tissue sections with doubtful morphology and intracytoplasmic melanin pigment was not appreciable.

\section{Results}

Total 90 cases of malignant melanoma analysed with biopsy examined in which 53 are non cutaneous and 37 cutaneous [Table 1]. The most common age group is 51-60 followed by 41-50. 9 cases are seen in very young age group below 30 year of age [Table 2].
Table 1 Site wise distribution of total cases

\begin{tabular}{|l|c|c|}
\hline Total cases & $\begin{array}{c}\text { Non cutaneous } \\
\text { melanoma }\end{array}$ & $\begin{array}{c}\text { Cutaneous } \\
\text { melanoma }\end{array}$ \\
\hline 90 & 53 & 37 \\
\hline
\end{tabular}

Table 2 Age group wise distribution of total cases

\begin{tabular}{|l|c|c|}
\hline Age group & No. Of cases & Precentage (\%) \\
\hline $1-10$ & 1 & 1.1 \\
\hline $11-20$ & 3 & 3.2 \\
\hline $21-30$ & 5 & 5.4 \\
\hline $31-40$ & 8 & 8.7 \\
\hline $41-50$ & 20 & 22.1 \\
\hline $51-60$ & 26 & 28.8 \\
\hline $61-70$ & 19 & 21.0 \\
\hline $71-80$ & 7 & 7.6 \\
\hline $81-90$ & 2 & 2.1 \\
\hline Total & $\mathbf{9 0}$ & $\mathbf{1 0 0}$ \\
\hline
\end{tabular}

In our study male $(\mathrm{n}=50)$ are more common involved then female $(n=40)$.

Table 3 The age and sex distribution of cutaneous melanoma are listed

\begin{tabular}{|l|c|c|c|}
\hline Age group & Male(20) & Female(17) & Total (37) \\
\hline $1-10$ & 0 & 0 & 0 \\
\hline $11-20$ & 1 & 1 & 2 \\
\hline $21-30$ & 3 & 2 & 5 \\
\hline $31-40$ & 4 & 3 & 7 \\
\hline $41-50$ & 5 & 4 & 9 \\
\hline $51-60$ & 3 & 3 & 6 \\
\hline $61-70$ & 2 & 2 & 4 \\
\hline $71-80$ & 1 & 1 & 2 \\
\hline $81-90$ & 1 & 1 & 2 \\
\hline Total & $\mathbf{2 0}$ & $\mathbf{1 7}$ & $\mathbf{3 7}$ \\
\hline
\end{tabular}

Table 4 The age and sex wise distribution of non cutaneous melanoma are listed

\begin{tabular}{|l|c|c|c|}
\hline Age group & Male( 30) & Female (23) & Total (53) \\
\hline $1-10$ & 1 & 0 & 1 \\
\hline $11-20$ & 1 & 1 & 2 \\
\hline $21-30$ & 4 & 3 & 7 \\
\hline $31-40$ & 4 & 3 & 7 \\
\hline $41-50$ & 10 & 5 & 15 \\
\hline $51-60$ & 8 & 7 & 15 \\
\hline $61-70$ & 2 & 4 & 6 \\
\hline $71-80$ & 0 & 0 & 0 \\
\hline $81-90$ & 0 & 0 & 0 \\
\hline Total & 30 & 23 & 53 \\
\hline
\end{tabular}


Table 5 Site distribution of cutaneous melanoma listed

\begin{tabular}{|l|c|}
\hline Site & No of cases \\
\hline Sole & 12 \\
\hline Dorsum of foot & 10 \\
\hline Thigh & 7 \\
\hline Scalp & 5 \\
\hline Vulva & 3 \\
\hline Total & $\mathbf{3 7}$ \\
\hline
\end{tabular}

Table 6 Site distribution of non- cutaneous melanoma

\begin{tabular}{|l|c|}
\hline Site & No of cases \\
\hline Ractum & 12 \\
\hline Anal canal & 7 \\
\hline Nasal and sinonasal & 6 \\
\hline Orbital & 6 \\
\hline Oral cavity & 5 \\
\hline Vagina & 5 \\
\hline Lymph node & 4 \\
\hline Small intestine- colon & 3 \\
\hline Right temporal region & 2 \\
\hline Paraspinal soft tissue & 1 \\
\hline Spinal mass & 1 \\
\hline Frontal sol & 1 \\
\hline TOTAL & $\mathbf{5 3}$ \\
\hline
\end{tabular}

Table 7 Clark's level in relation to site

\begin{tabular}{|l|c|c|c|c|c|c|}
\hline Site & $\begin{array}{c}\text { Clark } \\
\text { I }\end{array}$ & $\begin{array}{c}\text { Clark } \\
\text { II }\end{array}$ & $\begin{array}{c}\text { Clark } \\
\text { III }\end{array}$ & $\begin{array}{c}\text { Clark } \\
\text { IV }\end{array}$ & $\begin{array}{c}\text { Clark } \\
\text { V }\end{array}$ & TOTAL \\
\hline Sole & 2 & 1 & 5 & 2 & 2 & 12 \\
\hline $\begin{array}{l}\text { Dorsum } \\
\text { of foot }\end{array}$ & 1 & 1 & 5 & 2 & 1 & 10 \\
\hline thigh & 0 & 0 & 4 & 2 & 1 & 7 \\
\hline Scalp & 0 & 0 & 3 & 1 & 1 & 3 \\
\hline Vulva & 0 & 0 & 2 & 1 & 0 & 3 \\
\hline
\end{tabular}

Table 8 Histomorphological type wise distribution of cutaneous melanoma

\begin{tabular}{|l|c|c|c|}
\hline $\begin{array}{l}\text { Acral } \\
\text { lentigious }\end{array}$ & $\begin{array}{c}\text { Superficial } \\
\text { spreading }\end{array}$ & Nodular & Total \\
\hline 7 & 13 & 17 & 37 \\
\hline
\end{tabular}

\section{Discussion}

Melanoma is a cancer of pigment laden cellsmelanocytes which derive from pluripotent neural crest stem cells. It migrates to and differentiates within the epidermis as well as to other extracutaneous pigment-containing sites. ${ }^{(5)}$

According to the literature the incidence and mortality are decreasing in younger populations, but incidence rates are still increasing in the older age groups. ${ }^{(2)}$
In our study, the highest incidence was observed in the fifth-sixth decade of life, was similar to the previous studies. ${ }^{(6)}$

In our study only $4.4 \%$ melanomas occurring in persons younger than 20 years of age and $1.1 \%$ in children. Pappo et all study also show almost similar result. ${ }^{(7)}$

The reported male predilection of malignant melanoma in the literature was concordance in this study. ${ }^{(2,6,8)}$ Wanebo et al. and Castel et al. reported a female preponderance in their series. ${ }^{(9 \text {, }}$ 10)

In our study non-cutaneous melanoma are common type of melanoma 53cases (58.59\%) then cutaneous melanoma 37 cases $(41.1 \%)$ which is dis-concordance with other studies by Chang and Mukhopadhyay et al. who reported $82 \%$ and $78.57 \%$ of the cases, respectively, to be of cutaneous origin. ${ }^{(6,11)}$

In our study nodular cutaneous melanoma (45.9\%) was the most common type of melanoma, which is expected because in India, superficial spreading melanoma and nodular melanoma are commonly found. ${ }^{(12)}$

In our study, among cutaneous melanoma, the lower extremities were the most common site, which is accordance with the previous studies by Radhika et al. And Tjarta et al. ${ }^{(13,14)}$

According to the literature, lower extremities are the most common site of involvement in males, while the trunk is the most common site in females. However, in western studies, the opposite has been observed. In our study, maximum number of cutaneous cases were observed in lower extremities such as the sole and dorsum of foot in both sexes. A similar result was found by Kumar et al and other studies. ${ }^{(8,15,16)}$

In our study, lymph node was the most common site of metastasis. These results were similar with the Radhika et al and other studies studies. ${ }^{(6,13)}$

The prognosis of non- cutaneous melanoma is poor than primary cutaneous melanomas because of the higher stage at the time of diagnosis, the rich vascular and lymphatic supply of mucosal sites, and the lack of clinical suspicion of the 
tumor because of its rarity. The initial treatment is surgical resection, but the location may make it technically difficult to obtain complete tumor removal. Unlike cutaneous melanoma, sun exposure is not a risk factor for noncutaneous melanomas. Dark-skinned individuals may have a higher incidence of some noncutaneous melanomas such as ano-rectal melanomas. It is important for clinicians and pathologists to recognize primary noncutaneous melanomas to provide early detection and optimum management. ${ }^{(4)}$

Prasad et al found 15 cases in upper alveolus and 9 in hard palate, whereas in our study, we found five cases $(5.5 \%)$ in oral cavity malignant melanoma. ${ }^{(17)}$

Oral melanosis has suggested as a predisposing factor for the development of oral melanoma in $30-73 \%$ of the patients. Although the incidence of melanosis in India is low, there is a higher occurrence of primary oral melanoma, thereby contraindicating this hypothesis ${ }^{\left({ }^{(18}\right)}$

Ano-rectal melanoma is an extremely rare malignancy with worse prognosis that is thought to arise from melanocytes of mucosa around the anorectal junction. It constitutes about $0.05 \%$ of all anorectal malignancies. The largest series from a single center included 85 cases from the Memorial Sloan-Kettering Cancer Center, reported by Brady et al. in 1995. It is mostly seen in the sixth decade, with a female predominance. In our study, we found only 7 cases of ano-rectal melanoma. ${ }^{(19)}$

Tariq et al. conducted a clinicopathological study on 61 cases of anorectal melanoma for a period 10 years. In their study, $8 \%$ of the cases had distant metastasis to liver and vertebral column. In our study, 4 cases initially presented with lymph node metastasis and 1 case had frontal SOL. ${ }^{(20)}$

Melanoma of female genitalia comprises $3-7 \%$ of all melanocytic tumors, vulval skin being a common site (1-2\%). Of all the vulval malignant neoplasms, melanoma comprises $3.6 \%-10 \%$, in our study 3 cases $(3.3 \%)$ of vulvar melanoma found. ${ }^{(21)}$
Research about vulvar melanoma is limited due to the low incidence of cases per center and low numbers of international collaborative studies or meta-analyses. ${ }^{(22)}$

It is known that melanoma has a wide spectrum of histologic differentiation- epithelial, hematologic, mesenchymal, and neural tumors, so when necessary, immunohistochemistry is the primary tool to establish the correct diagnosis. HMB-45,S100 protein and Melan-A are the three most useful immunomarkers to identify melanocytes and to diagnose melanomas. ${ }^{(23)}$

S-100 protein is the most sensitive marker of melanocytic differentiation. Probably 95\% of primary cutaneous melanomas express this marker. ${ }^{(24)}$

HMB-45 has an additional utility to differentiating benign melanocytic lesions from MM as benign lesions (e.g., dermal nevi) tend to show decreased expression with lesion depth/maturation, whereas melanoma often shows more consistent staining in the deeper component. However, many exceptions present, particularly in the setting of certain nevic variants of melanoma. so we used S100, HMB-45 and melan $\mathrm{A}$ for confirming melanocytic origin and differentiating benign from malignant lesions. ${ }^{(25)}$

The prognostic factors in primary skin melanoma were studied by Clark (1969) and Breslow (1970) who observed that tumor thickness was an important indicator of behavior.

In our study, the majority of cases presented in Clark's level III and IV, which is consistent with earlier studies reported by Mukhopadhyay et al. and Kuno et al. ${ }^{(6,26)}$

\section{Conclusion}

Malignant melanoma is aggressive tumor, more common in male then female. Nodular melanoma and superficial spreading was commonest histologic type of malignant melanoma in our population. 


\section{Acknowledgement}

I would like to thank my teachers, husband, parents, colleagues and technical staff of department of pathology, SMS Medical Collage Jaipur for helping and guiding me for this study.

\section{References}

1. Hui SK, Lau KH, Leung CY, Tang WYM, Chong LY, Lo KK. Cutaneous melanoma: clinical features of 32 Hong Kong Chinese patients. Hong Kong J Dermatol Venereol. 2005; 13:130-40.

2. Sharma K, Mohanti BK, Rath GK. Malignant melanoma: A retrospective series from a regional cancer center in India. J Cancer Res Ther 2009; 5:173-80.

3. Lens MB, Dawes M. Global perspectives of contemporary epidemiological trends of cutaneous malignant melanoma. $\mathrm{Br} \mathrm{J}$ Dermatol 2004; 150:179-85.

4. $\mathrm{Wu}$ E, Golitz LE. Primary noncutaneous melanoma. Clin Lab Med 2000; 20:73144.

5. Ali Z, Yousaf N, Larkin J. Melanoma epidemiology, biology and prognosis. EJC Suppl 2013; 11:81-91.

6. Mukhopadhyay S, Ghosh S, Siddhartha D, Mitra PK. A clinicopathological study of malignant melanoma with special reference to atypical presentation. Indian J Pathol Microbiol 2008; 51:485-8.

7. Pappo AS. Melanoma in children and adolescents. Eur J Cancer 2003; 39:265161.

8. Thapa S, Ghosh A, Ghartimagar D, Prasad $\mathrm{T}$, Narasimhan $\mathrm{R}$, Talwar $\mathrm{O}$, et al. Clinicopathological study of malignant melanoma at tertiary care centre. JNMA J Nepal Med Assoc 2017; 56:132-6.

9. Wanebo HJ, Cooper PH, Young DV, Harpole DH, Kaiser DL. Prognostic factors in head and neck melanoma. Effect of lesion location. Cancer 1988; 62:831-7.

10. Castel T, Baradad M, Castro J, Mascaró JM, García-Valdecasas JC, Grande L, et al. Primary malignant melanoma of the skin. Retrospective study of 375 cases. Clinical aspects and histology. Med Clin (Barc) 1990; 94:246-9.

11. Chang JW. Cutaneous melanoma: Taiwan experience and literature review. Chang Gung Med J 2010; 33:602-12.

12. Chopra A, Walia RL, Gupta S, Sethi PS, Begga HK. Nodular malignant melanomasecondary to carcinoma rectum. Indian $\mathbf{J}$ Dermatol Venerol Leprol 1997; 63:327-9

13. Radhika K, Prayaga AK, Sundaram C. A clinicopathologic study of malignant melanoma based on cytomorphology. Indian J Cancer 2016; 53:199-203.

14. 14-Tjarta A, Kanoko M, Ueda M, Hamzah M, Cipto H, lchihashi M, et al. Rare case of melanoma studied for its histopathological features in Indonesia. Med J Indones 2000; 9:93-9

15. Kumar V, Vishnoi JR, Kori CG, Gupta S, Misra S, Akhtar N, et al. Primary malignant melanoma of oral cavity: A tertiary care center experience. Natl J Maxillofac Surg 2015;6:167-71.

16. Vayer A, Lefor AT. Cutaneous melanoma in African-Americans. South Med J 1993; $86: 181-2$

17. Prasad ML, Busam KJ, Patel SG, HoshawWoodard S, Shah JP, Huvos AG, et al. Clinicopathologic differences in malignant melanoma arising in oral squamous and sinonasal respiratory mucosa of the upper aerodigestive tract. Arch Pathol Lab Med 2003; 127:997-1002

18. Padhye A, D'souza J. Oral malignant melanoma: A silent killer? J Indian Soc Periodontol 2011; 15:425-8

19. Buissin D, Sterle A, Schmiegelow P, Wassenberg D, Ambe PC. Primary anorectal malignant melanoma: A rare but aggressive tumor: Report of a case. World J Surg Oncol 2015; 13:12

20. Tariq MU, Ud Din N, Ud Din NF, Fatima $\mathrm{S}$, Ahmad Z. Malignant melanoma of 
anorectal region: A clinicopathologic study of 61 cases. Ann Diagn Pathol 2014; 18:275-81.

21. Ali Z, Yousaf N, Larkin J. Melanoma epidemiology, biology and prognosis. EJC Suppl 2013; 11:81-91.

22. Heinzelmann-Schwarz VA, Nixdorf S, Valadan M, Diczbalis M, Olivier J, Otton $\mathrm{G}$, et al. A clinicopathological review of 33 patients with vulvar melanoma identifies c-KIT as a prognostic marker. Int J Mol Med 2014; 33:784-94.

23. Ohsie SJ, Sarantopoulos GP, Cochran AJ, Binder SW. Immunohistochemical characteristics of melanoma. J Cutan Pathol 2008; 35:433-44.

24. Prieto VG, Shea CR. Use of immunohistochemistry in melanocytic lesions. J Cutan Pathol 2008; 35 Suppl 2:1-0

25. Compton LA, Murphy GF, Lian CG. Diagnostic immunohistochemistry in cutaneous neoplasia: An update. Dermatopathology (Basel) 2015; 2:15-42.

26. Kuno Y, Ishihara K, Yamazaki N, Mukai $\mathrm{K}$. Clinical and pathological features of cutaneous malignant melanoma: A retrospective analysis of 124 Japanese patients. Jpn J Clin Oncol 1996; 26:14451. 